Article

\title{
Density Functional Theory Study of Arsenate Adsorption onto Alumina Surfaces
}

\author{
Katie W. Corum, Ali Abbaspour Tamijani and Sara E. Mason * \\ Department of Chemistry, University of Iowa, Iowa City, IA 52242, USA; katharine-corum@uiowa.edu (K.W.C.); \\ abbaspour@uiowa.edu (A.A.T.) \\ * Correspondence: sara-mason@uiowa.edu; Tel.: +1-319-335-2761
}

Received: 1 February 2018; Accepted: 23 February 2018; Published: 1 March 2018

\begin{abstract}
Atomistic modeling of mineral-water interfaces offers a way of confirming (or refuting) experimental information about structure and reactivity. Molecular-level understanding, such as orbital-based descriptions of bonding, can be developed from charge density and electronic structure analysis. First-principles calculations can be used to identify weaknesses in empirical models. This provides direction on how to propose more robust representations of systems of increasing size that accurately represent the underlying physical factors governing reactivity. In this study, inner-sphere complex geometries of arsenate on hydrated alumina surfaces are modeled at the density functional theory (DFT)-continuum solvent level. According to experimental studies, arsenate binds to alumina surfaces in a bidentate binuclear (BB) fashion. While the DFT calculations support the preference of the $\mathrm{BB}$ configuration, the optimized geometries show distortion from the ideal tetrahedral geometry of the arsenic atom. This finding suggests that steric factors, and not just coordination arguments, influences reactivity. The $\mathrm{O}_{\text {surf }}-\mathrm{As}-\mathrm{O}_{\text {surf }}$ angle for the more favorable arsenate configurations is closest to the ideal tetrahedral angle of $109.5^{\circ}$. Comparing the results of arsenate adsorption using a small cluster model with a periodic slab model, we report that the two model geometries yield results that differ qualitatively and quantitatively. This relates the steric factors and rigidity of the surface models.
\end{abstract}

Keywords: adsorption; arsenate contamination; computer simulations; DFT; mineral-solution interfaces

\section{Introduction}

Modeling heterogeneous reactions at the interface between mineral surfaces and natural waters provides information about processes such as pollutant transport, transformation, bioavailability, and fate. However, owing to the structural and compositional variety of real mineral surfaces, as well as variable ion concentrations and $\mathrm{pH}$ in natural waters, it is difficult to find a favorable balance between model accuracy and complexity. As such, it is necessary to study analog systems in which the structure, composition, and other properties of interest can be precisely controlled and examined in detail. Transition metal oxide surfaces have been long-standing model systems for this purpose [1,2]. Building on earlier work on clean single-crystal mineral surfaces studied under ultra-high vacuum conditions [3-6], experimental studies of hydrated surfaces have emerged to address questions, such as how exposed surfaces transform under geochemical conditions [7-10]. Experimental studies of $\mathrm{Al}$ and $\mathrm{Fe}$ (hydr)oxide surfaces are prolific [11-17], as these materials have a natural abundance and reactivity towards aqueous contaminants. As an example, numerous studies conducted by Catalano and co-workers can be mentioned [18-21]. In one study, the (012) plane of the $\alpha-\mathrm{Al}_{2} \mathrm{O}_{3}$-water interface [18] was probed through high-resolution $X$-ray reflectivity experiments and fitting analysis. These experiments concluded that the most probable surface structure has a stoichiometric termination, on which dangling $\mathrm{Al}$ bonds are capped with hydroxyl groups (from 
dissociative water adsorption). In another work, Trainor et al. reported the termination of this surface as being dominated by a "missing-Al" layer structure [22]. In this surface termination, the five-fold Al layer of the defect-free surface, as proposed by Catalano et al. is removed. Mason et al. later addressed the discrepancy between the two accounts, by using first-principles calculations and thermodynamics [23]. The modeling work demonstrated that the two different terminations are both thermodynamically favorable, and that surface preparation conditions and measurement settings likely give rise to observations of the two terminations. Experimental and theoretical studies of the isostructural hematite surfaces have also been carried out, resulting in similar conclusions [24,25]. More recently, experimental and theoretical studies are building up from the mineral-water interface, in order to obtain structural information about interfacial water ordering $[19,26]$.

The robust structural models for mineral-water interfaces, such as the (012) and (001) planes of corundum $\alpha-\mathrm{Al}_{2} \mathrm{O}_{3}$ and hematite $\alpha-\mathrm{Fe}_{2} \mathrm{O}_{3}$, form a basis for detailed studies of aqueous contaminant adsorption. As a case study, inner-sphere complexation of divalent $\mathrm{Pb}$ on single crystal surfaces has been characterized using grazing-incidence X-ray absorption spectroscopy (GI-XAS). In a series of studies by Bargar and co-workers [27], the binding of $\mathrm{Pb}(\mathrm{II})$ on the (001) and (012) planes of alumina and hematite were interpreted using a bond-valence analysis of the experimental structures. Based on bonding principles proposed by Pauling [28-32], and later modeled by Brown [29], the bond-valence terms $s_{i j}$ between atoms $i$ and $j$ are defined as:

$$
s_{i j}=\exp \left(\frac{R_{i j}^{0}-R_{i j}}{B}\right)
$$

In this formalism, $s_{i j}$ is a measure of bond strength between two species $i$ and $j, B$ is an empirical parameter, and $R_{i j}$ is the separation between hypothetical atoms $i$ and $j$. Further, $R_{i j}^{0}$ denotes the tabulated value for the internuclear distance between $i$ and $j$ when the bond strength is 1 . Some parameters have been previously reported by Brown and Altermatt [29]. Based on the bond-valence (BV) model, the parameters are determined such that the sum of all $s_{i j}$ values is equal to the absolute value of the oxidation number for that ion. While there is no rigorous way to relate valence sums to bond energies, it is assumed that structures which yield BV sums close to ideal values are more stable than those in which the sums deviate from ideal values. The way in which the BV model is applied to geochemical surface science is to first consider the hydrated surface structure in the absence of adsorbates (other than water and water dissociation products). The terminal oxygen functional groups of the mineral are the potential reactive sites. Atomic distances between oxygen and its nearest neighbor pairing ions (either the cation(s) of the mineral or hydrogen, the latter using a modified BV form [1]) are used in the bulk parametrized model to arrive at BV sums. The BV sums then reveal whether the oxygen functional group is under-saturated-and thus likely or plausible to form additional bonds-or saturated. The analysis can be repeated with the addition of adsorbates, and by considering (de)protonation events. The coordination of surface oxygen to a cation or cations is often denoted using Roman numerals, such as $\mathrm{O}(\mathrm{I})$ for a singly-coordinated functional group, and protonation can be written in such as $\mathrm{O}(\mathrm{I}) \mathrm{H}$ for a singly-coordinated hydroxyl group. In this fashion, Bargar and co-workers were able to use GI-XAS bond distance information and BV modeling to conclude that, for the case of $\mathrm{Pb}$ (II) inner-sphere adsorption on $\mathrm{Al}_{2} \mathrm{O}_{3}$, the following ranking in sorption complex geometry is expected: $\mathrm{O}(\mathrm{III})-\mathrm{Pb}>\mathrm{O}(\mathrm{I}) \mathrm{H}-\mathrm{Pb}>\mathrm{O}(\mathrm{II})-\mathrm{Pb}$. O(II)H-Pb is expected to be over-saturated and thus unlikely to occur.

The BV-based rationalization of sorption complex stability has been used in conjunction with the well-vetted structural models of (012) and (001) alumina-water interfaces, in order to interpret observed differences in reactivity as a function of surface structure. For example, the stoichiometric (012) surface structure exposes $\mathrm{O}(\mathrm{III}) \mathrm{H}$ and $\mathrm{O}(\mathrm{I}) \mathrm{H}$ groups, expected to be reactive, based on BV analysis. The (001) surface is terminated solely by $\mathrm{O}(\mathrm{II}) \mathrm{H}$ groups, which are expected to be saturated and unreactive towards inner-sphere complex formation. In this example, the BV predictions by functional group type 
offers a plausible interpretation for the experimentally observed trend that the (001) plane is relatively inert (forming mostly outer-sphere complexes with $\mathrm{Pb}(\mathrm{II})$ ) relative to the (012) plane, which forms inner-sphere complexes.

As recently summarized by $\mathrm{Xu}$ and Catalano [20], the reactivity of oxygen functional groups in aluminum hydroxides can be thought of in terms of interactions with water as well as adsorbates. The pKa values associated with protonation and deprotonation events of $\mathrm{O}(\mathrm{I}) \mathrm{H}$ compared to $\mathrm{O}$ (II)H groups supports the inert nature of $\mathrm{O}(\mathrm{II}) \mathrm{H}$ groups, again attributed to saturation arguments. The study went on to use the aluminum hydroxide polymorphs of gibbsite, terminated by $\mathrm{O}(\mathrm{II}) \mathrm{H}$ groups, and bayerite, terminated by a mixture of $\mathrm{O}(\mathrm{II}) \mathrm{H} / \mathrm{O}(\mathrm{I}) \mathrm{H}$ groups, to directly assess reactivity towards arsenate, in terms of surface functional group type. The macroscopic adsorption studies show that the $\mathrm{O}(\mathrm{I}) \mathrm{H}$-rich bayerite adsorbs more arsenate per normalized surface area than the $\mathrm{O}(\mathrm{II}) \mathrm{H}$-terminated gibbsite. The results support the idea that reactivity (in terms of tendency to form inner-sphere complexes with adsorbates) tracks with functional group distribution, and that these trends can be conceptualized in terms of oxygen functional group coordination and protonation.

The success of BV-based structure-reactivity relationships has provided a basis for geochemical surface complexation models, such as the charge distribution multisite complexation CD-MUSIC model, to interpret ionic adsorption on mineral-water interfaces [33]. However, the advent of tractable first-principles modeling of sorption processes has provided a means for electronic structure analysis and interpretation, as well as more details about sorption complex geometry than can be obtained experimentally. Aspects of mineral-water interface reactivity that can be described accurately by first-principles calculations include dynamic bonding, adsorption-induced surface relaxations, and bonding interpretations based on chemical orbital descriptions. For example, in a first-principles molecular dynamics study of the silica water, Leung and co-workers [34] identified changes in oxygen functional group protonation states over the course of the simulations, which offered a new interpretation of the acid-base behavior of the surface [34]. Further discussion of recent quantum mechanical modeling contributions to geochemical surface science can be found in the literature [16,35-38].

While computational chemistry approaches to the mineral-water interface structure-reactivity relationship enable a detailed molecular-level understanding of sorption bonds, the use of these methods requires convergence studies with regard to computational parameters and the structural model chosen to represent the system. Density functional theory (DFT) modeling that employs the pseudopotential approach and periodic boundary conditions to model a hydrated metal surface requires preliminary testing in advance of research calculations. Examples include the need to test the pseudopotentials used to represent electron-nucleus interactions, convergence with respect to the energy sampling in $k$-space, and how the choice of exchange-correlation function affects the structural and electronic properties of the system. As recently reviewed [39], some online pseudopotential libraries are not reliable, while others, such as the GBRV [40] have been shown to enable highly reproducible results.

In terms of the choice of model geometry, so-called cluster models and periodic repeat slab models are two popular categories. When clusters are used to represent metal (hydr)oxide surfaces, the model usually contains an average of two metal atoms with approximately 10-14 oxygen atoms of varying protonation state, often to achieve neutrality. Paul et al. has modeled sulfate adsorption onto Fe clusters. They used Fe clusters that contained two Fe atoms, ten $\mathrm{O}$ atoms, and a varying number of hydrogen atoms [16]. They concluded that both the cluster models and the surface had acceptable bond agreement, using Extended X-ray Absorption Fine Structure (EXAFS) data. However, the long-range interactions are not and cannot be present in the Fe cluster models due to the size constraints. Baltrusaitis et al. have used iron and aluminum clusters to study bicarbonate adsorption [41]. In their study, two tetrahedral metal atoms were linked by one bridging oxygen atom, and different configurations of bicarbonate were modelled. Another study by Watts et al. employed a tri-nuclear Fe cluster structure, to model As adsorption [15]. In this Fe structure, two Fe atoms 
are octahedrally coordinated, while one Fe atom only has five bonds. These authors compared the extended Fe structure, as well as an Fe surface, to EXAFS studies, and concluded that while both systems matched bonding patterns to the EXAFS data, the surface showed precise bond distance agreement compared to the cluster. Another study that questions the reliability of such cluster models is performed by Pierre-Louis et al. These authors used $\mathrm{Al}, \mathrm{Fe}$ and, $\mathrm{Al} / \mathrm{Fe}$ structures to model $\mathrm{CO}_{2}$ adsorption [42]. This study has modelled monodentate and bidentate $\mathrm{CO}_{2}$ adsorption on $\mathrm{Al}_{2}$ clusters, $\mathrm{Fe}_{2}$ clusters, and $\mathrm{Al} / \mathrm{Fe}$ clusters (one $\mathrm{Al}$ atom and one $\mathrm{Fe}$ atom). Upon comparing the results of these computational models with EXAFS data, the authors recognized that these small metal clusters do not correctly mimic the $\mathrm{Al} / \mathrm{Fe}$ surface adsorption process. However, they are sufficient in determining the bonding interactions of adsorbents. In another study, Pahlavan and Pakiari [43] have investigated the adsorption of ethylene atop iron surfaces, using mono- and bi-nuclear Fe clusters. The study also focuses on the effect of chlorine addition on the adsorption strength of small organic specimen on iron surfaces. Whilst the small cluster approach has fared successfully for nanoparticle simulations and more [44], it does not include certain crucial effects, such as surface-mediated lateral interactions and other coverage-dependent behaviors. Neglecting these effects can potentially skew the results unfavorably. Overall, the approach appears to be excessively facile and lacks the elements required to provide a meaningful and realistic insight into the adsorption phenomenon as a whole. It is noteworthy that the justification for the use of small clusters to simulate surface adsorption properties is given rise to by the same rationale that assumes that the surface effects can be considered local, as approximated in the BV model. In other words, the BV model implicitly assumes that the local effects are the only variable that can influence the bonding between the surface and the adsorbate. As such, comparing the cluster model and the periodic model can be advantageous, in the sense that the comparison will provide us with insight as to whether or not this is a valid approximation.

The aim of this study is to further develop the fundamental understanding of arsenate adsorption on hydrated alumina surfaces through first-principles DFT calculations. By choosing a system that is both highly relevant and well-studied, it is possible to assess and compare the DFT results with experimental information and long-standing BV arguments about reactivity. This work also compares the results of periodic slab models and cluster models of aluminum hydroxide-arsenate complexes, which offer the modeling community an assessment of the strengths and weaknesses of the two model geometries. Our small aluminum cluster contains two $\mathrm{Al}$ atoms, ten $\mathrm{O}$ atoms, and enough $\mathrm{H}$ atoms to maintain the charge neutrality principle. We hypothesize that the adsorption energy cannot be the same on both the surface and the clusters, due to their inherent structural differences.

Arsenic (As) contamination of ground water is a global problem of high profile. It is considered to have influenced more than 137 million people in 70 countries. As is one of the most toxic ions found in drinking water $[45,46]$. Arsenic poisoning is more commonplace in continents from Southeast Asia, such as Bangladesh, Vietnam, and India [47-50]. Negative health impacts caused by As include respiratory issues, cardiovascular disease, diabetes, and skin and lungs cancers, and As poisoning is potentially fatal [51-54]. As can exist in a range of oxidation states, depending on the environmental systems. It is most commonly found in the form of a +3 or +5 cation, with the former cation being more toxic than the latter [55]. Water in nature tends to have a $\mathrm{pH}$ range of 4-9. In water, $\mathrm{As}(\mathrm{V})$ is more stable than $\mathrm{As}(\mathrm{III})$. Wilson et al. have reported that within a $\mathrm{pH}$ range of about $2-7, \mathrm{H}_{2} \mathrm{AsO}_{4}{ }^{-}$is the stable form of $\mathrm{As}(\mathrm{V})$, whereas at a $\mathrm{pH}$ above $7, \mathrm{HAsO}_{4}{ }^{2-}$ is the most stable form [55].

There is a consensus in literature as to how arsenate binds to aluminum or iron surfaces, based on EXAFS data [11-14]. When arsenate binds to $\alpha$-alumina, $\gamma$-alumina, and gibbsite, these studies reveal that arsenate preferentially binds to the aluminum surface in a bidentate, binuclear manner (which can also be called corner-sharing). This means that the As binds to two oxygen atoms, which are bound to two separate $\mathrm{Al}$ atoms. This type of configuration will be referenced as bidentate binuclear (BB) throughout this paper. Arsenate adsorption onto iron oxide surfaces is also found to be more favorable in a bidentate binuclear configuration [15-17]. In a comprehensive study done by Watts and colleagues, the adsorption of arsenic atop mineral substrates and its current state in the 
literature has been reviewed. Part of this work is devoted to systematically analyzing the influence of surface charge, hydration, and oxidation states on adsorption geometries and energetics of arsenic onto iron-(oxyhydr)oxide models [15]. The work has concluded that properties such as reaction rates, thermodynamics, and structural results are biased towards the choice of the DFT method and should be further validated. On the experimental end of the spectrum, Catalano and co-workers have investigated the adsorption of arsenate on the (012) planes of alumina and hematite using X-ray scattering measurements [21]. Their work concludes that arsenate adsorption on the aforementioned surfaces is bimodal, namely, inner- and outer-sphere complexes. However, the authors have also commented that it is experimentally difficult to determine whether or not the outer-sphere arsenate is occurring in the presence of inner-sphere effects. Nonetheless, it has suggested that the inner-sphere adsorption takes place through bridging bidentate ligation, in agreement with the pertinent literature. The study has also revealed that the average Al-As distance for the inner-sphere adsorption is $3.2 \AA$. EXAFS studies show that the $\mathrm{As}(\mathrm{V})-\mathrm{O}_{\text {surf }}$ bond distance on $\alpha$-alumina, gibbsite, and $\gamma$-alumina are $1.69 \pm 0.005 \AA, 1.68 \pm 0.02 \AA$ and $1.69 \pm 0.01 \AA$, respectively. For all these surfaces, the coordination number of As is $\sim 4$ [12-14]. Using bond geometry analysis, we modelled a variety of configurations for As adsorption in order to compare EXAFS bond distances with our computational studies.

\section{Materials and Methods}

Structural calculations of $\alpha-\mathrm{Al}_{2} \mathrm{O}_{3}$ (012) and small Al clusters were carried out using DFT, as implemented in the $\mathrm{DMol}^{3}$ code developed by Delley [56,57]. Aperiodic all-electron DFT calculations were performed using the generalized gradient approximation (GGA) of Perdew, Burke, and Ernzerhof (PBE) [58], with a double-numeric-plus polarization atom-centered basis set. A real-space basis set cutoff of $4.50 \AA$ was used. Lattice optimizations for the bulk $\alpha-\mathrm{Al}_{2} \mathrm{O}_{3}$ were converged with respect to $k$-points using a Monkhorst-Pack (MP) grid of $4 \times 4 \times 4$ to sample the Brillouin zone. The optimized lattice constants are $4.821 \AA(+1.3 \%)$ and $13.111 \AA(+0.9 \%)$ for alumina. These values are in excellent agreement with experimental data (as indicated in parentheses) [59]. Our lattice parameter values are also consistent with previously-reported DFT-GGA results [60-64].

All surface and cluster geometry optimization calculations were carried out with aqueous effects, accounted for through the Conductor-like Screening Model (COSMO). This scheme applies the dielectric constant chosen to model water that can simulate environmental conditions [65]. When using COSMO, the cluster is placed into a cavity within the implicit water, as determined by the solvent dielectric constant. The charge distribution of the cluster polarizes the dielectric continuum. The response to the medium is described by screening charges on the cavity's exterior. The structural optimizations used a convergence criterion of $0.03 \mathrm{eV} / \AA$.

In the present work, we focused on arsenate adsorption binding to three different terminations of the (012) alumina surfaces, as well as on small Al clusters in multiple configurations. Using the alpha-numeric surface stoichiometry naming scheme of Lo et al. [24], we modelled arsenate on the C3, C4, and A3 terminations of the (012) surface (Figure 1). For the slab calculations, $2 \times 2$ supercells were used, and the $k$-point density was appropriately reduced to $2 \times 2 \times 1$. With a surface area of approximately $100 \AA^{2}$, this rectangle-shaped slab accommodates a surface coverage of 0.06 atoms $/ \AA^{2}$. The three surface terminations are shown in Figure 1. These surfaces differ in terms of the type(s) of exposed oxygen functional groups. The C4 and C3 surfaces have a missing layer of Al cations compared to the A3 surface. The A3 and C3 surfaces are capped with hydroxyls, while the C4 surface contains water groups on its top and bottom. With these differences, the C3, C4, and A3 slabs consist of 12,12, and $14 \mathrm{O}$ layers, and 6, 6, and 8 Al layers, respectively. In its bare form, A3 termination has singly- and triply-coordinated $\mathrm{O}(\mathrm{O}(\mathrm{I})$ and $\mathrm{O}(\mathrm{III})$, respectively) atoms on its outermost layer. C3 and $\mathrm{C} 4$ however, have singly-, doubly- and triply-coordinated $\mathrm{O}$ atoms on their topmost layer $(\mathrm{O}(\mathrm{I})$, $\mathrm{O}$ (II) and $\mathrm{O}(\mathrm{III})$, respectively). These surfaces are ideal for examining the adsorption of arsenate onto the (012) facet of $\mathrm{Al}_{2} \mathrm{O}_{3}$, due to their stabilities and range of exposed oxygen functional groups. These three surfaces are the most energetically favored terminations of the (012) facet in the aqueous 
environment, as per Mason et al. [23]. For all these three surfaces, $25 \AA$ of vacuum space was added to separate the periodic images along the $c$ direction. We modelled arsenate adsorption in three different configurations on each surface. Each surface contained inversion symmetry, so there was one arsenate ion bound to each side of the surface, as recently demonstrated to be appropriate for an accurate representation of surface electronic structure [66].
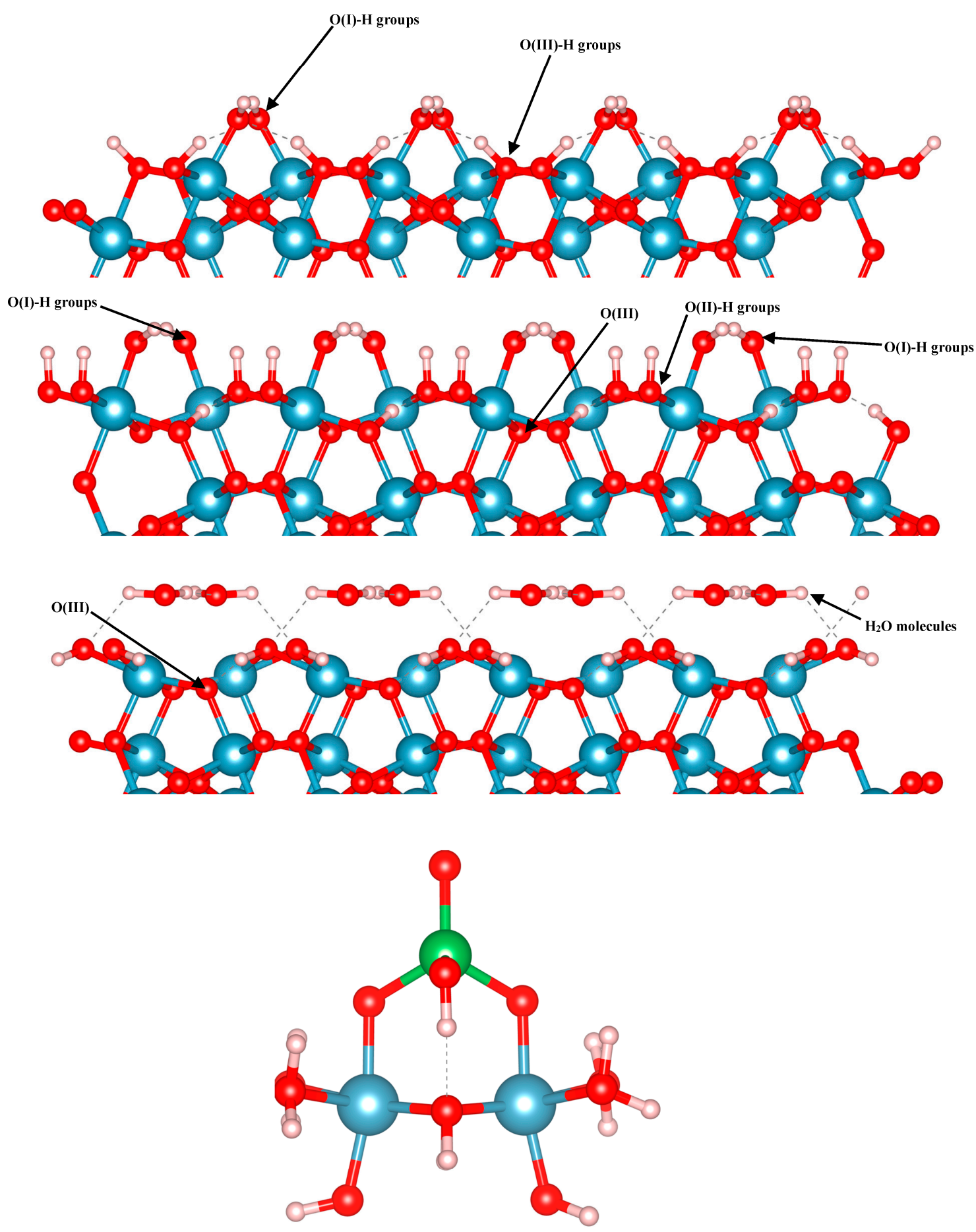

Figure 1. OH-terminated A3 (top), OH-terminated C3 with the "missing Al layer" (second from the top), and $\mathrm{H}_{2} \mathrm{O}$-terminated $\mathrm{C} 4$ (third from the top) alumina surfaces, and the Al-BB cluster model (bottom). Aluminum, arsenic, oxygen, and hydrogen are blue, green, red, and white spheres, respectively. 
The small aluminum hydroxide cluster models are composed of two Al octahedra, which contain bound hydroxyl and bound water groups so that the clusters remain neutral. This structure was based on cluster model figures in previously-reported literature, and is also shown in Figure 1 [16,42,67]. We modelled arsenate adsorption in multiple configurations to compare with the surface complex models, and in all cases the cluster models are overall charge neutral.

In the periodic slab model, on each surface, $\mathrm{As}(\mathrm{V})$ surface complex geometries were initiated to explore different possible adsorption configurations, and to span bonding environments involving the various types of oxygen functional groups. Following the language in current literature, arsenate can bind in a bidentate mononuclear (BM) fashion or a bidentate binuclear (BB) one [12-14]. A BM adsorption occurs when the two oxygen atoms bound to the arsenate are bound to the same $\mathrm{Al}$ atom. This configuration can also be labeled as edge-sharing. A BB adsorption occurs when the two oxygen atoms bound to the arsenate are bound to two different $\mathrm{Al}$ atoms. For the cluster models, we tested three different BM and one BB conformers. For all three surface models, we examined two different $\mathrm{BB}$ configurations and one BM configuration. For the single protonation surfaces and the cluster calculations, we used Equations (1a) and (1b), respectively. The adsorption energy, $E_{a d s}$, is determined using the DFT total energy information, appropriately weighted by stoichiometric coefficients, and reported per As(V) surface complex.

$$
\begin{gathered}
\mathrm{Al}_{2} \mathrm{O}_{3}+2 \mathrm{AsO}_{2}(\mathrm{OH})_{2}{ }^{-}+2 \mathrm{H}_{3} \mathrm{O}^{+} \rightarrow(\mathrm{AsO}(\mathrm{OH}))_{2} \mathrm{Al}_{2} \mathrm{O}_{3}+6 \mathrm{H}_{2} \mathrm{O} \\
\text { Cluster }+\mathrm{AsO}_{2}(\mathrm{OH})_{2}{ }^{-}+\mathrm{H}_{3} \mathrm{O}^{+} \rightarrow \mathrm{AsO}(\mathrm{OH}) \text { Cluster }+3 \mathrm{H}_{2} \mathrm{O}
\end{gathered}
$$

\section{Results and Discussion}

The modeled adsorption results are analyzed in terms of optimized geometry, energetics, and electronic structure. Truncated side views of the optimized structures are shown in Figure 2 (A3), Figure 3 (C3), and Figure 4 (C4). The local geometry of the most favorable As configuration on the A3, C3, and C4 structures is shown in Figures 2-4. In Table 1, we report the adsorption energies for all modeled surfaces using Equations (1a) and (1b). We use a naming scheme for all our structures that will now be described. For the three A3 structures, we use the names HHBB, HVBB, and HVBM, which represent a hill-hill bidentate binuclear structure, a hill-valley bidentate binuclear structure, and a hill-valley bidentate mononuclear structure, where a hill signifies an $\mathrm{O}$ atom from the top surface $\mathrm{O}$ layer, and valley signifies an $\mathrm{O}$ atom from the second $\mathrm{O}$ surface layer.

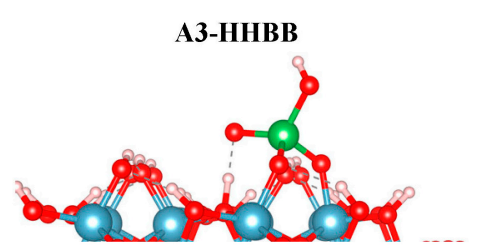

$E_{\text {ads }}=-1.15 \mathrm{eV}$

$\mathrm{r}_{\mathrm{m}}=1.742 \AA$

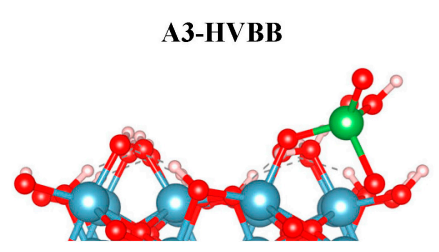

$E_{\text {ads }}=-0.57 \mathrm{eV}$

$\mathrm{r}_{\mathrm{m}}=1.813 \AA$

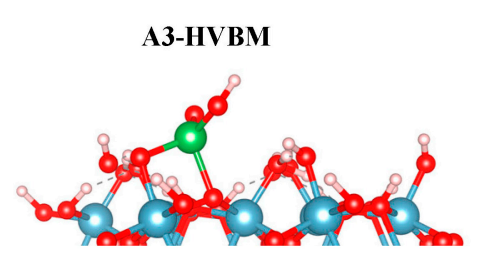

$E_{\text {ads }}=-0.10 \mathrm{eV}$

$\mathrm{r}_{\mathrm{m}}=1.811 \AA$

Figure 2. The A3 optimized structures. From left to right: hill-hill bidentate binuclear structure (HHBB), hill-valley bidentate binuclear structure (HVBB), and hill-valley bidentate mononuclear structure (HVBM). Aluminum, oxygen, hydrogen, and arsenic are represented by the colors blue, red, white, and green respectively. $E_{\text {ads }}$ and $\mathrm{r}_{\mathrm{m}}$ are the adsorption energies and averaged As- $\mathrm{O}_{\text {surf }}$ distances, respectively.

For the C3 surface, we modelled an HHBB and HVBM structure, which represent a hill-hill bidentate binuclear structure and a hill-valley bidentate mononuclear structure. The HVBM structure optimizes to a HHBB (hill-hill bidentate binuclear) configuration. Thus, we call the HVBM structure HVBM (HHBB). After optimization, the major difference between C3 HHBB and C3 HVBM (HHBB) is 
the location of certain $\mathrm{H}$ atoms. When the HVBM (HHBB) structure optimizes, proton rearrangement occurs and ultimately makes the C3 HVBM (HHBB) structure more favorable than C3 HHBB. This is evident from their respective adsorption energies. The C3 HVBM (HHBB) has an adsorption energy of $-2.30 \mathrm{eV}$, while the adsorption energy for the $\mathrm{C} 3 \mathrm{HHBB}$ configuration is $-2.26 \mathrm{eV}$. We rearranged the protons on the $\mathrm{C} 3 \mathrm{HHBB}$ surface to better resemble the C3 HVBM (HHBB) surface. We call this surface C3 HHBB-H, for a hill-hill bidentate binuclear structure with a proton rearrangement.

\section{C3-НHВB}

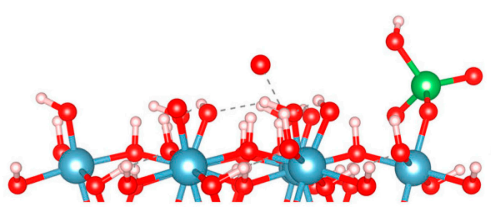

$$
\begin{aligned}
& E_{\mathrm{ads}}=-1.35 \mathrm{eV} \\
& r_{\mathrm{m}}=1.742 \AA
\end{aligned}
$$

C3-HVBM(НHBВ)

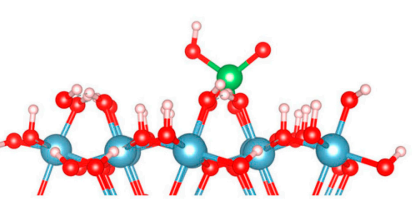

$E_{\text {ads }}=-2.30 \mathrm{eV}$

$r_{m}=1.763 \AA$
C3-HНBB-H

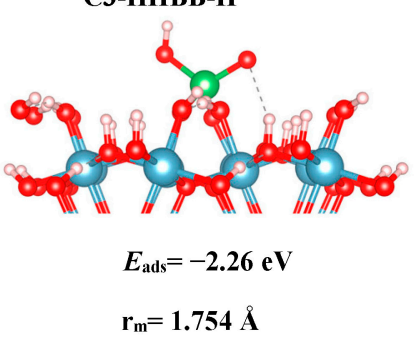

Figure 3. The $\mathrm{C} 3$ optimized structures. From left to right: HHBB, HVBM (HHBB), and hill-hill bidentate binuclear structure with a proton rearrangement (HHBB-H). Aluminum, oxygen, hydrogen, and arsenic are represented by the colors blue, red, white, and green respectively. $E_{\mathrm{ads}}$ and $\mathrm{r}_{\mathrm{m}}$ are the adsorption energies and averaged As- $\mathrm{O}_{\text {surf }}$ distances, respectively.

C4-HHBB

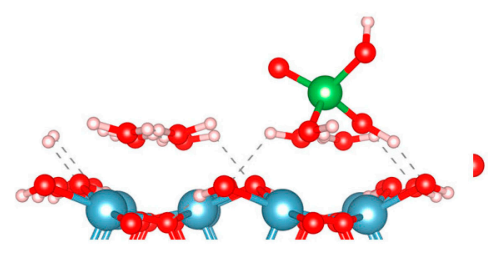

$E_{\mathrm{ads}}=-0.88 \mathrm{eV}$

$\mathrm{r}_{\mathrm{m}}=1.783 \AA$
C4-HHVTB

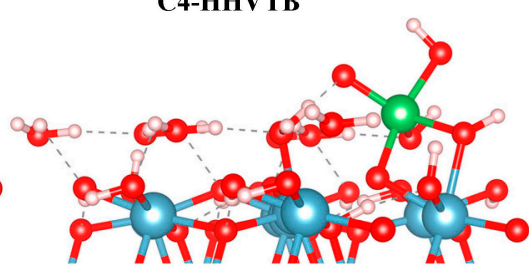

$E_{\text {ads }}=-1.29 \mathrm{eV}$

$\mathrm{r}_{\mathrm{m}}=1.750 \AA$
C4-HVBM

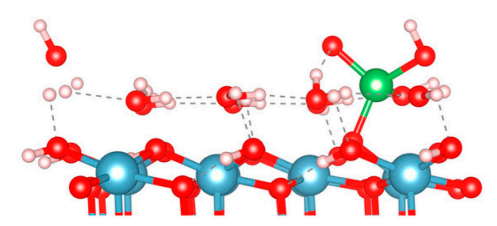

$E_{\text {ads }}=-0.17 \mathrm{eV}$

$\mathrm{r}_{\mathrm{m}}=1.779 \AA$

Figure 4. The C4 optimized structures. From left to right: HHBB, HHVTB, and HVBM. Aluminum, oxygen, hydrogen, and arsenic are represented by the colors blue, red, white, and green respectively. $E_{\mathrm{ads}}$ and $\mathrm{r}_{\mathrm{m}}$ are the adsorption energies and averaged $\mathrm{As}-\mathrm{O}_{\text {surf }}$ distances, respectively.

Table 1. Calculated $E_{\text {ads }}$ for all structures, based on Equation (1a) for the surfaces and (1b) for the cluster model.

\begin{tabular}{cc}
\hline & $\boldsymbol{E}_{\text {ads }}(\mathbf{e V})$ \\
\hline A3 HHBB & -1.15 \\
A3 HVBB & -0.57 \\
A3 HVBM & -0.10 \\
C3 HHBB & -1.35 \\
C3 HVBM (HHBB) & -2.30 \\
C3 HHBB-H & -2.26 \\
C4 HHBB & -0.88 \\
C4 HHVTB & -1.29 \\
C4 HVBM & -0.17 \\
Al-BB & -2.52 \\
Al-BM1 & -2.17 \\
Al-BM2 & -2.25 \\
Al-BM3 & -2.09 \\
\hline
\end{tabular}

Initially, we chose to model two As(V) complexes on the C4 surface, HHBB and HVBM, which represents hill-hill bidentate binuclear and hill-valley bidentate mononuclear configurations. 
We realized that the way in which the arsenate is situated on top of two surface waters for the HHBB configuration will result in a bidentate or tridentate bonding to the surface. We denoted the HHBB structure that resulted in a tridentate configuration on the C4 surface as HHVTB. This structure represents a hill-hill-valley tridentate binuclear configuration. The distance between the hill $\mathrm{O}$ and O valley is $2.39 \AA$ in the optimized C4-HHVTB configuration. In this configuration, arsenate is experiencing a significant amount of distortion. The coordination number for arsenate is almost 5 in a trigonal bipyramidal environment. This can be observed in the As- $\mathrm{O}_{\text {surf }}-\mathrm{As}$ angle being $92.6^{\circ}$, which is far from the ideal tetrahedral angle of $109.5^{\circ}$.

Based on the DFT results, we can note reactivity trends in the $\mathrm{As}(\mathrm{V}) / \mathrm{Al}_{2} \mathrm{O}_{3}$ surface models. The reaction energies, as reported in Table 1 for all systems, suggest that a BB configuration is more favorable than a BM configuration. For the A3 surface, the two BB configurations are $0.47 \mathrm{eV}$ and $1.05 \mathrm{eV}$ lower in energy, respectively, than the HVBM structure. For the C3 surface, the BM configuration optimized to a $\mathrm{BB}$ configuration, thus resulting in a $\mathrm{BM}$ configuration not being stable for the $\mathrm{C} 3$ surface. For the C4 surface, the two BB configurations are $0.71 \mathrm{eV}$ and $1.12 \mathrm{eV}$ lower in energy than in the BM configuration, respectively.

We also found a trend between the hill-hill $(\mathrm{HH})$ and the hill-valley (HV) configurations, with the $\mathrm{HH}$ configurations being more favorable than the HV configurations. For the A3 structure, the HHBB structure was the most favorable by at least $0.58 \mathrm{eV}$, compared to the HV structures. For the C3 surface, once again, an HV configuration could not be optimized. The HV configuration optimized to a $\mathrm{HH}$ configuration. For the $\mathrm{C} 4$ surface, the $\mathrm{HH}$ configuration is more favorable than the $\mathrm{HV}$ configuration by $0.71 \mathrm{eV}$. However, the most favorable $\mathrm{C} 4$ surface was seen as the arsenate forms a tridentate configuration and binds to two hill oxygen atoms as well as one valley oxygen atom.

Even though Table 1 shows that there is a significant energy difference between the BB and BM, as well as the $\mathrm{HH}$ and $\mathrm{HV}$ configurations, we do not see a significant difference in the bond lengths between the surface/cluster $\mathrm{O}$ atom and the As atom. We label this as $\mathrm{As}-\mathrm{O}_{\text {surf }}$ distance. We report our findings in Table 2. For A3, we find that the most favorable structure (HHBB) has the shortest As- $\mathrm{O}_{\text {surf }}$ bond length by $0.071 \AA$. For the most favorable $\mathrm{C} 3$ structure, the $\mathrm{As}-\mathrm{O}_{\text {surf }}$ bond length is longer by only $0.021 \AA$. It is hard to compare the separations in the bonding of the C4 structure, since one structure forms three bonds to the surface, while two structures only form two bonds to the surface. The structure that binds in a tridentate fashion has longer bond lengths than the bidentate configurations.

Table 2. As- $\mathrm{O}_{\text {surf }}$ bond distances in $\AA$ for the model sorption structures. O(I), O(II) and O(III) refer to singly-, doubly- and triply-coordinated surface oxygen, respectively. Two As- $\mathrm{O}_{\text {surf }}$ bond distances are reported for each bidentate structure, and three are reported for the tridentate one.

\begin{tabular}{cccc}
\hline & As-O(I) & As-O(II) & As-O(III) \\
\hline A3 HHBB & $1.718,1.766$ & & \\
A3 HVBB & 1.721 & & 1.909 \\
A3 HVBM & 1.724 & & \\
C3 HHBB & $1.737,1.744$ & & \\
C3 HVBM (HHBB) & $1.758,1.772$ & & \\
C3 HHBB-H & $1.751,1.755$ & 1.810 \\
C4 HHBB & & & \\
C4 HHVTB & 1.870 & & \\
C4 HVBM & & & \\
Al-BB & $1.744,1.745$ & \\
Al-BM1 & $1.764,1.769$ & \\
Al-BM2 & $1.750,1.756$ & & \\
Al-BM3 & $1.740,1.772$ & & \\
\hline
\end{tabular}

The As $-\mathrm{O}_{\text {surf }}$ distances range from $1.718 \AA$ to $1.870 \AA$ for the most favorable structures. All these distances are in agreement with the experimental value of $1.69 \AA$ [13]. Although this value is measured for a microscopic sample spanning planes other than the (012), the agreement is reasonable. 
Electronic structure analyses were carried out for arsenate-adsorbed surface terminations in their most energetically-preferred forms, namely, A3-HHBB, C3-HHBB-H, and C4-HHVTB. The analyses were done to characterize the bonding nature between the adsorbate and the surfaces. Projected density of states (PDOS) calculations were performed to examine the As-O bonding. Covalent interactions can be inspected by means of PDOS calculations, by noting the intensity of projections onto different states (such as the oxygen $\mathrm{p}$ states and arsenate $\mathrm{d}$ states) over common energy ranges. The fractional fillings of states can also be deduced from the PDOS, by considering the relative area under the PDOS, below the Fermi level, relative to the total area, providing information about ionization. The hybridization of As in $\mathrm{AsO}_{4}{ }^{3-}$ is $\mathrm{sp}^{3} \mathrm{~d}$. As such, we have plotted the s, $\mathrm{p}$, and d states of As and the $\mathrm{s}$ and $\mathrm{p}$ states of the $\mathrm{O}$ atom of the surface attached to the As. The PDOS graphs of the optimized configurations of arsenate atop alumina are plotted with respect to their intensities in Figure 5 It should be kept in mind that the A3-HHBB, C3-HHBB-H, and C4-HHVTB plots are for singly-protonated structures, and the Fermi level is offset to $0.00 \mathrm{eV}$. The Fermi energy level is offset to 0.00 to obtain the relative energy changes of various states more easily and clearly.

The A3-HHBB As(V)/ $\mathrm{Al}_{2} \mathrm{O}_{3}$ complex is the most favorable on the A3 surface, with $E_{\mathrm{ads}}=-1.15 \mathrm{eV}$. Only singly-coordinated oxygen functional groups form bonds to As in this corner-sharing configuration, with distances of $1.718 \AA$ and $1.766 \AA$.

Based on the relatively favorable adsorption energy, common functional group type through which As binds, and similar bond distances, we expect that the PDOS of the two oxygen atoms will reflect favorable, similar bonding patterns. As shown in Figure 5, the HOMO state has a significant contribution from As d orbitals between $-4.10 \mathrm{eV}$ and $+0.68 \mathrm{eV}$. Also, the LUMO states have a certain degrees of $\mathrm{d}$ orbitals between $6.80 \mathrm{eV}$ and $9.52 \mathrm{eV}$. This is consistent with a partially-filled As d-band. Two sharp intense peaks were observed at $\sim-9.52 \mathrm{eV}$ and $\sim+5.44 \mathrm{eV}$. We interpret these peaks as the result of an overlap between As s and $\mathrm{O} p$ orbitals. The superposition of As and $\mathrm{O} p$ states was observed over broader energy ranges between $-8.16 \mathrm{eV}$ and $0.0 \mathrm{eV}$, as well as between $6.80 \mathrm{eV}$ and $10.89 \mathrm{eV}$. The latter peak was of higher intensity as compared to the former.

Another noticeable aspect of this chart is the interaction between the As $\mathrm{d}$ and $\mathrm{O} p$ orbitals that occurs between 6.80 and $10.89 \mathrm{eV}$. Examining the C3-HHBB-H PDOS (Figure 5), we see that the overlap of the $\mathrm{p}$ states of $\mathrm{O}$ and As occurs within the range of $-8.16 \mathrm{eV}$ to $0.00 \mathrm{eV}$, and to a far lesser extent between $5.44 \mathrm{eV}$ and $10.89 \mathrm{eV}$. The overlap between $\mathrm{O} \mathrm{p}$ and As d states falls within the same range as As $\mathrm{p}$ and $\mathrm{O} \mathrm{p}$, as well as within $2.72 \mathrm{eV}$ and $0.00 \mathrm{eV}$. Overall, the PDOS for the C3-HHBB-H configuration follows the same general trends, as compared to the one for A3-HHBB. However, the C4-HHVTB structure is different from the A3-HHBB and C3-HHBB-H, in that the As is bound to two different types of surface $\mathrm{O}$ atoms. Hereafter, the surface $\mathrm{O}$ atoms of $\mathrm{C4}$-HHVTB will be labeled as $\mathrm{O}$ (I) (for lower-layer surface O) and O(II) (for upper-layer surface O). Therefore, acronyms O(II)-s and $\mathrm{O}(\mathrm{I})$-p stand for the s state of upper-layer surface $\mathrm{O}$ and, $\mathrm{p}$ states of lower-layer surface $\mathrm{O}$, respectively. Interestingly, $\mathrm{O}(\mathrm{II})-\mathrm{p}$ and $\mathrm{O}(\mathrm{I})$-p superimpose on one another in several regimes, such as at $2.72 \mathrm{eV}$ and $5.44 \mathrm{eV}$. As $\mathrm{p}$ and $\mathrm{O}$ (II) $\mathrm{p}$ show the same behavior at $-6.80 \mathrm{eV}$. On the other hand, except for the region close to $-6.53 \mathrm{eV}$, the remainder of the bonding regime (below the Fermi level) exhibits different levels of overlap between the As p states and those of $\mathrm{O}(\mathrm{I})$, compared to As p states and O(III) p states. In other words, whenever the peaks of As $p$ states are close to that of $\mathrm{O}$ (II) $\mathrm{p}$ states, they are far less similar to peaks of $\mathrm{O}(\mathrm{I}) \mathrm{p}$ states, and vice versa. This is due to the fact that $\mathrm{O}$ (I) and $\mathrm{O}$ (II) are situated in two different coordination environments (singly-coordinated for $\mathrm{O}(\mathrm{I})$ while doubly-coordinated for $\mathrm{O}(\mathrm{II})$ ). Comparing these three structures, it can be concluded that the energy matching found between the surface oxygen states and those of the As adsorbate states supports the fact that these three structures are the most energetically-favorable adsorption configurations. 

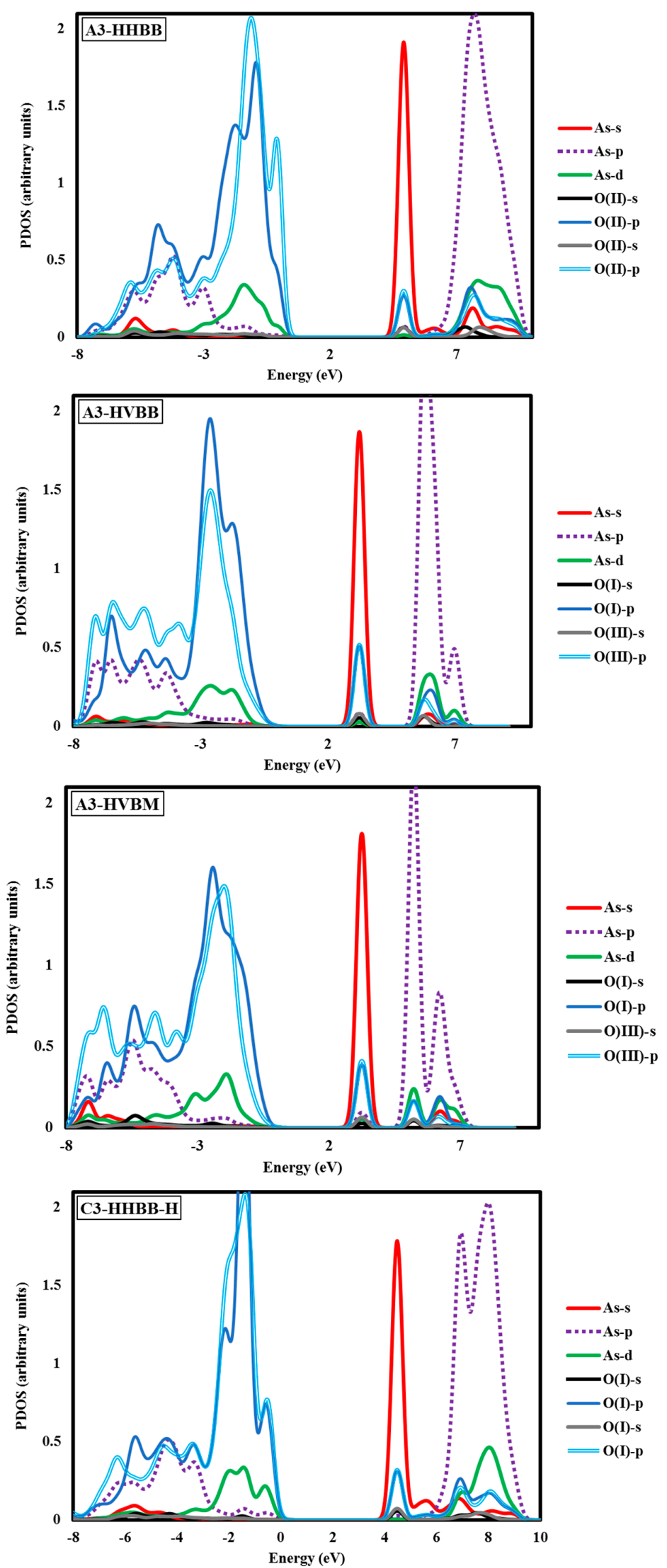

Figure 5. Cont. 


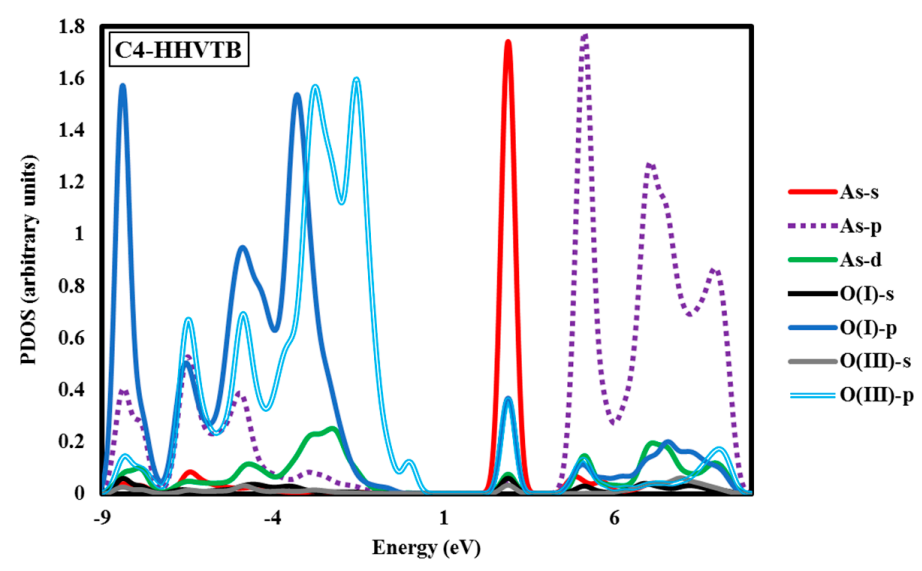

Figure 5. Projected density of states for the adsorption of arsenate on the (012) surface of $\mathrm{Al}_{2} \mathrm{O}_{3}$.

The DFT values of $E_{\text {ads }}$ for the $\mathrm{As}(\mathrm{V}) / \mathrm{Al}_{2} \mathrm{O}_{3}$ complexes, modeled on the $\mathrm{A} 3$ surface, span more than $1 \mathrm{eV}$. We inspected the PDOS and sorption complex geometries to find an explanation for this wide energy range. However, the PDOS plots for A3-HHBB, A3-HVBB, and A3-HVBM show no major differences (see Figure 5). As previously noted, the As-O bond distances did not display variations to explain the trend in the values of $E_{\text {ads }}$. However, the geometry of the adsorption complexes does show that the tetrahedrally coordinated $\mathrm{As}(\mathrm{V})$ undergoes significant distortions in the less-favorable configurations. We interpret the adsorption-induced perturbations in the $\mathrm{As}(\mathrm{V})$ tetrahedral angles to be the root cause for noticeable fluctuation in values of $E_{\text {ads }}$. For instance, the $\mathrm{O}_{\text {surf }}-\mathrm{As}-\mathrm{O}_{\text {surf }}$ angle is very close to its ideal value of $104.5^{\circ}$ for the A3-HHBB structure $\left(105^{\circ}\right)$, which is energetically preferred. The same angles for A3-HVBB and A3-HVBM are $101.5^{\circ}$ and $88.5^{\circ}$, respectively. Thus, while the PDOS shows that ultimately the favorable As-O overlap is achieved, doing so requires distortion from the ideal $\mathrm{T}_{\mathrm{d}}$ symmetry, and thus the adsorption becomes less energetically favorable.

The above case study demonstrates that $\mathrm{As}(\mathrm{V}) / \mathrm{Al}_{2} \mathrm{O}_{3}$ structures with significantly varying $E_{\text {ads }}$ can have similar PDOS. This suggests that arsenate can form covalent bonding interactions with surface oxygen atoms, even when distorted considerably from ideal $\mathrm{T}_{\mathrm{d}}$ geometry. We also wanted to analyze the PDOS for incidents in which As-O bonding gives rise to distinct PDOS features. Owing to the variety of oxygen functional groups involved in As bonding, we chose the C4-HHVTB structure with one acidic $\mathrm{H}$ atom on the adsorbate. The PDOS plot for this structure is shown in Figure 5. The C4-HHVTB conformer is bound to two different surface $\mathrm{O}$ atoms, two doubly-coordinated and one triply-coordinated. In the PDOS plot, we have only included the overlap between the charge densities of the non-hydrated, singly-coordinated $\mathrm{O}$ and the doubly-coordinated $\mathrm{O}$ on the surface of the As atom of the arsenate. The separation between the As atom and the $\mathrm{O}$ (II) (i.e., the doubly-coordinated $\mathrm{O}$ ) is $1.840 \AA$, whereas the distance between the As and the $\mathrm{O}(\mathrm{I})$ (the singly-coordinated $\mathrm{O}$ ) is $1.755 \AA$. Interestingly, the PDOS shows an energy shift of approximately $0.60 \mathrm{eV}$ towards the more positive regime of the energy spectrum for $\mathrm{O}(\mathrm{I})$, as compared to $\mathrm{O}(\mathrm{II})$. In other words, although $\mathrm{BV}$ theory would dictate that the longer bond (As-O(II)) is thought to be weaker than the shorter bond (As-O(I)), the PDOS diagram shows more destabilization for the shorter bond (As-O(I)) as compared to the longer one (As-O(II)). This finding is in line with the results of an earlier work reported by Ramadugu and Mason [68], regarding the violation of direct bond length-bond strength arguments in $\mathrm{Sb}(\mathrm{V}) / \mathrm{Al}_{2} \mathrm{O}_{3}$ structures.

Another interesting aspect of this PDOS is the distribution of the As d states. The relatively small amount of $\mathrm{d}$ in the bonding states is due to the presence of $\mathrm{d}$ states in the $\mathrm{sp}^{3} \mathrm{~d}$ hybridized atomic orbitals, and the remainder of the $\mathrm{d}$ states in the anti-bonding region is attributable to empty $\mathrm{d}$ states of the As atom. Using literature parameter values [27], we computed the BV sums for As in all of the DFT-optimized geometries. These values are collected in Table 3. As it can be seen in Table 3, the BV sum values are notably smaller than the oxidation state of the As (i.e., +5). Based on the BV approach, 
this outcome will mean that As is under-saturated. This can be due to the fact that GGA-PBE method systematically underestimates the bond energy, which will in turn result in overestimating the bond lengths [69-71]. Another possibility for the underestimation of the As BV sum is the fact that the chemical environment of $\mathrm{As}(\mathrm{V})$ in the surface complex is unlike that of bulk $\mathrm{As}(\mathrm{V})$ oxides used to parametrize the BV model.

Table 3. Calculated BV sums for As, as adsorbed onto different surfaces.

\begin{tabular}{cc}
\hline Surface-Config. & BV-sum at As (v.u.) \\
\hline A3-HHBB & 4.38 \\
A3-HVBM & 4.17 \\
C3-HVBM(HHBB) & 4.24 \\
C3-HHBB & 4.39 \\
C4-HHVTB & 4.21 \\
C4-HHBB & 4.18 \\
\hline
\end{tabular}

However, even taking into account a possible systematic error, due to differences between experimentally determined bulk parameters and DFT surface results, there is no direct correlation between the adsorption energies and the BV sums for As.

The present study can be compared to previous work in which the adsorption of $\mathrm{Sb}(\mathrm{V})$ on the same alumina surfaces was investigated using the same DFT methods [69].

Based on the results of this study, the adsorption of $\mathrm{Sb}(\mathrm{OH})_{6}^{-}$is energetically preferred for bidentate and tridentate conformers. While $\mathrm{Sb}(\mathrm{V})$ and $\mathrm{As}(\mathrm{V})$ have a common electron configuration of $\mathrm{sp}^{3} \mathrm{~d}$, the higher coordination number of the antimony means that the surface complex maintains more distal ligands. While both adsorbed species exhibit considerable distortions from ideal angles, as discussed, the impact is different. In the case of $\mathrm{Sb}(\mathrm{V}) / \mathrm{Al}_{2} \mathrm{O}_{3}$, the $\mathrm{Sb}-\mathrm{O}_{\text {surf }}$ bonds are not able to achieve desirable overlap in the distorted structures, as confirmed by the PDOS analysis. In the case of $\mathrm{As}(\mathrm{V}) / \mathrm{Al}_{2} \mathrm{O}_{3}$, the overlap is ultimately comparable, regardless of distortion of the As coordination environment in the surface complex. We interpret this disparity in terms of the differences in coordination number. The adsorption of arsenate, a tetrahedrally-coordinated oxyanion, creates an adsorption environment with a lower symmetry as compared to $\mathrm{Sb}$.

Finally, we discuss the results of the cluster models. One BB As(V) configuration and three BM $\mathrm{As}(\mathrm{V})$ configurations for the Al clusters are modelled, and the optimized geometries are shown in Figure 6. Inspection of the As-O bond distances in Table 2 shows that for the cluster model, the distances are generally longer than for the slab model. In both the small cluster model and the periodic slab model, the $\mathrm{Al}-\mathrm{O}_{\text {surf }}$ distance for the adsorbate-free species is shorter than that of arsenate-adsorbed one. The Al- $\mathrm{O}_{\text {cluster }}$ axial separation is $1.816 \AA$ for the freestanding cluster, whereas the same distance for the As-adsorbed complex is $1.882 \AA$. The Al-O(I) distance for the A3 bare surface is $1.815 \AA$. The same distance for the A3-HHBB configuration is $1.867 \AA$ and $1.827 \AA$ for the two surface $\mathrm{O}$ (I) atoms involved in the inner-sphere adsorption environment. This bond elongation upon adsorption is consistent with what is observed for the slab model. However, the bond elongation in the cluster model is greater than that of the surface. We attribute this to the fact that the slab model is more rigid than the flexible small cluster model.

The results of $\mathrm{As}(\mathrm{V})$ adsorption to the cluster models also provides an opportunity to compare the results quantitatively and qualitatively to those calculated for the surface. In this sense, we note that the Al-BB cluster model is most similar to the A3HHBB surface model, in that both can be described as corner sharing or bridging bidentate complexes. The Al-BM1-3 are all edge sharing, and thus comparable to the A3-HVBM surface complex. While both the cluster and surface models predict BB-type complexes to be energetically favorable, relative to the edge-sharing BM type, the absolute and relative values of $E_{\text {ads }}$ vary considerably. Specifically, while the A3HHBB complex is favored by $1.05 \mathrm{eV}$ relative to the AsHVBM complex, the cluster A1BB complex is only favored by $0.27-0.43 \mathrm{eV}$. 
Furthermore, the values of $E_{\text {ads }}$ for the A3HHBB is $-1.15 \mathrm{eV}$, while that of the analogous Al-BB is $-2.52 \mathrm{eV}$, or more than twice as large in magnitude. The $\mathrm{O}_{\text {cluster }}-\mathrm{As}-\mathrm{O}_{\text {cluster }}$ angle was found to be very similar to that of a freestanding $\mathrm{T}_{\mathrm{d}}$ structure $\left(104.6^{\circ}\right)$ in the $\mathrm{BB}$ configuration, for which the adsorption energy was computed to be $-2.52 \mathrm{eV}$. This configuration was also found to be the most stable one amongst our various clusters. On the other hand, the least energetically favorable structure, BM3, with an adsorption energy of $-2.09 \mathrm{eV}$, exhibited an $\mathrm{O}_{\text {cluster }}-\mathrm{As}-\mathrm{O}_{\text {cluster }}$ angle of $92.14^{\circ}$. This steric hindrance has resulted in the lack of energetic favorability of this configuration.

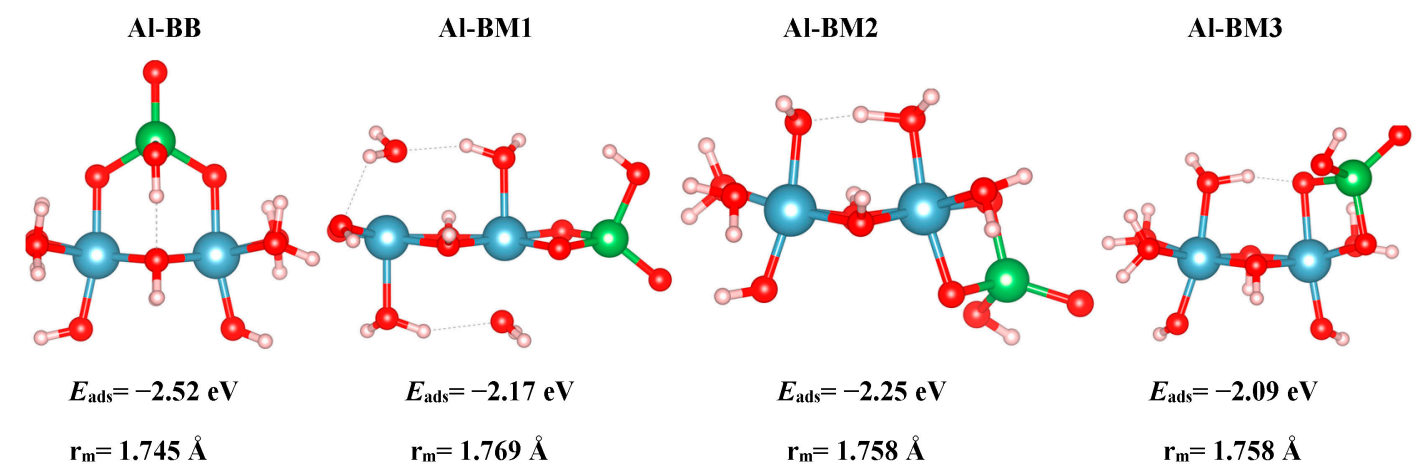

Figure 6. Optimized cluster structures. From left to right: Al-BB, Al-BM1, Al-BM2, and Al-BM3. Aluminum, oxygen, hydrogen, and arsenic are represented by the colors blue, red, white, and green respectively. $\mathrm{r}_{\mathrm{m}}$ is the As- $\mathrm{O}_{\text {cluster }}$ averaged distance for the As-cluster model.

For the $\mathrm{Al}$ clusters, the $\mathrm{BB}$ configuration has the shortest $\mathrm{A}-\mathrm{O}_{\text {cluster }}$ bond length of $1.745 \AA$. Our As- $\mathrm{O}_{\text {cluster }}$ separations are between $1.744 \AA$ and $1.772 \AA$. Hence, all of our calculated As- $\mathrm{O}_{\text {cluster }}$ distances are not only in agreement with their experimental counterpart [13], but also are similar to our computed As- $\mathrm{O}_{\text {surf }}$ separations. In an arsenate-free cluster, the $\mathrm{Al}-\mathrm{O}$ distance is $1.816 \AA$, whereas in an arsenate-adsorbed Al-BB cluster, this distance is $1.882 \AA$.

The agreement between the bond distances for the cluster model and the experimental result is also observed in the results of the work done by Watts et al. [16]. Based on their study, different configurations of the arsenate on a binuclear Fe cluster and a periodic $\alpha$-goethite (010) surface have been investigated. In both cases, the As-O separations matched well with their experimental counterpart (1.62-1.64 $\AA$ ). Their surface model predicted this distance to be $1.63 \AA$, whereas their cluster model assumed an As- $\mathrm{O}_{\text {cluster }}$ distance of $1.67 \AA$.

\section{Conclusions}

The DFT results presented here corroborate the consensus of experimental studies that $\mathrm{As}(\mathrm{V})$ prefers to form inner-sphere complexes to aluminum hydroxide surfaces in a bridging bidentate fashion. The $\mathrm{As}(\mathrm{V}) / \mathrm{Al}_{2} \mathrm{O}_{3}$ complex geometries and electronic structure analyses provide further insight into how distortions in the adsorbing oxoanion geometry influence reactivity, a factor that is not readily discernable from experiment and which is often excluded in empirical models. The steric influence of the surface, as modeled in periodic slab models, is not well-represented in small cluster models, and both qualitative and quantitative discrepancies were noted between the two categories of model geometries. While the basis of bond valence arguments as used in mineral-water interface reactivity are sound, it should be noted that the use of bulk parametrization, as well as assumptions of static protonation states and fixed geometries, can give rise to misleading conclusions. For example, the DFT results here support that surface complexes formed through singly-coordinated oxygen functional groups are more favorable than those formed through doubly-coordinated oxygen functional groups. However, the steric effects of the surface topology on the adsorbing oxoanion geometry, and not the oxygen functional group coordination alone, is shown to contribute to the trends in relative $\mathrm{As}(\mathrm{V}) / \mathrm{Al}_{2} \mathrm{O}_{3}$ stability. 
Acknowledgments: This work was supported by National Science Foundation CAREER Grant NSF-CHE 1254127 and the University of Iowa College of Liberal Arts and Sciences. The research was supported in part by computational resources provided by the University of Iowa and the College of Liberal Arts and Sciences. Summer research intern John Charles Ward is acknowledged for his contribution to preliminary calculations of this work. One of the authors, Ali Abbaspour Tamijani is to extend his gratitude towards Sai Kumar Ramadugu for his help during the course of PDOS calculations.

Author Contributions: Katie W. Corum and Ali Abbaspour Tamijani have made equal contributions to this work. Katie W. Corum calculated the adsorption geometries (energies). Ali Abbaspour Tamijani computed the electronic structure PDOS plots and bond valence sums, and analyzed them in correlation with the adsorption energetics. Sara E. Mason is the supervisor that has advised Katie W. Corum and Ali Abbaspour Tamijani during the course of this work. Katie W. Corum and Ali Abbaspour Tamijani have performed the calculations and analyzed the data, with the supervision/scientific guidance/assistance of Sara E. Mason.

Conflicts of Interest: The authors declare no conflict of interest.

\section{References}

1. Brown, G.E.; Henrich, V.E.; Casey, W.H.; Clark, D.L.; Eggleston, C.; Felmy, A.; Goodman, D.W.; Gratzel, M.; Maciel, G.; McCarthy, M.I.; et al. Metal oxide surfaces and their interactions with aqueous solutions and microbial organisms. Chem. Rev. 1999, 99, 77-174. [CrossRef] [PubMed]

2. Al-Abadleh, H.A.; Grassian, V.H. FT-IR study of water adsorption on aluminum oxide surfaces. Langmuir 2003, 19, 341-347. [CrossRef]

3. Verdozzi, C.; Jennison, D.R.; Schultz, P.A.; Sears, M.P. Sapphire (0001) surface, clean and with $d$-metal overlayers. Phys. Rev. Lett. 1999, 82, 799-802. [CrossRef]

4. Diebold, U.; Li, S.C.; Schmid, M. Oxide surface science. Annu. Rev. Phys. Chem. 2010, 61, 129-148. [CrossRef] [PubMed]

5. Wang, X.-G.; Weiss, W.; Shaikhutdinov, S.K.; Ritter, M.; Petersen, M.; Wagner, F.; Schlögl, R.; Scheffler, M. The hematite $\left(\alpha-\mathrm{Fe}_{2} \mathrm{O}_{3}\right)$ (0001) surface: Evidence for domains of distinct chemistry. Phys. Rev. Lett. 1998, 81, 1038-1041. [CrossRef]

6. Henrich, V.E. Fundamentals of gas-surface interactions on metal oxides. Appl. Surf. Sci. 1993, 72, $277-284$. [CrossRef]

7. Fenter, P.; Sturchio, N.C. Mineral-water interfacial structures revealed by synchrotron X-ray scattering. Prog. Surf. Sci. 2004, 77, 171-258. [CrossRef]

8. Petitto, S.C.; Tanwar, K.S.; Ghose, S.K.; Eng, P.J.; Trainor, T.P. Surface structure of magnetite (111) under hydrated conditions by crystal truncation rod diffraction. Surf. Sci. 2010, 604, 1082-1093. [CrossRef]

9. Eng, P.J.; Trainor, T.P.; Brown, G.E., Jr.; Waychunas, G.A.; Newville, M.; Sutton, S.R.; Rivers, M.L. Structure of the hydrated $\alpha-\mathrm{Al}_{2} \mathrm{O}_{3}$ (0001) surface. Science 2000, 288, 1029-1033. [CrossRef] [PubMed]

10. Trainor, T.P.; Chaka, A.M.; Eng, P.J.; Newville, M.; Waychunas, G.A.; Catalano, J.G.; Brown, G.E. Structure and reactivity of the hydrated hematite (0001) surface. Surf. Sci. 2004, 573, 204-224. [CrossRef]

11. Tang, Y.Z.; Reeder, R.J. Uranyl and arsenate cosorption on aluminum oxide surface. Geochim. Cosmochim. Acta 2009, 73, 2727-2743. [CrossRef]

12. Ladeira, A.C.Q.; Ciminelli, V.S.T.; Duarte, H.A.; Alves, M.C.M.; Ramos, A.Y. Mechanism of anion retention from EXAFS and density functional calculations: Arsenic(V) adsorbed on gibbsite. Geochim. Cosmochim. Acta 2001, 65, 1211-1217. [CrossRef]

13. Zhang, M.Y.; He, G.Z.; Pan, G. Structure and stability of arsenate adsorbed on $\alpha-\mathrm{Al}_{2} \mathrm{O}_{3}$ single-crystal surfaces investigated using grazing-incidence EXAFS measurement and DFT calculation. Chem. Geol. 2014, 389, 104-109. [CrossRef]

14. Li, W.; Harrington, R.; Tang, Y.Z.; Kubicki, J.D.; Aryanpour, M.; Reeder, R.J.; Parise, J.B.; Phillips, B.L. Differential pair distribution function study of the structure of arsenate adsorbed on nanocrystalline gamma-alumina. Environ. Sci. Technol. 2011, 45, 9687-9692. [CrossRef] [PubMed]

15. Watts, H.D.; Tribe, L.; Kubicki, J.D. Arsenic adsorption onto minerals: Connecting experimental observations with density functional theory calculations. Minerals 2014, 4, 208-240. [CrossRef]

16. Paul, K.W.; Kubicki, J.D.; Sparks, D.L. Sulphate adsorption at the Fe(hydr)oxide- $\mathrm{H}_{2} \mathrm{O}$ interface: Comparison of cluster and periodic slab DFT predictions. Eur. J. Soil Sci. 2007, 58, 978-988. [CrossRef] 
17. Sherman, D.M.; Randall, S.R. Surface complexation of arsenie(V) to iron(III) (hydr)oxides: Structural mechanism from ab initio molecular geometries and EXAFS spectroscopy. Geochim. Cosmochim. Acta 2003, 67, 4223-4230. [CrossRef]

18. Catalano, J.G.; Park, C.; Zhang, Z.; Fenter, P. Termination and water adsorption at the $\alpha-\mathrm{Al}_{2} \mathrm{O}_{3}(012)-$ aqueous solution interface. Langmuir 2006, 22, 4668-4673. [CrossRef] [PubMed]

19. Catalano, J.G.; Fenter, P.; Park, C. Interfacial water structure on the (012) surface of hematite: Ordering and reactivity in comparison with corundum. Geochim. Cosmochim. Acta 2007, 71, 5313-5324. [CrossRef]

20. Xu, T.; Catalano, J.G. Impacts of surface site coordination on arsenate adsorption: Macroscopic uptake and binding mechanisms on aluminum hydroxide surfaces. Langmuir 2016, 32, 13261-13269. [CrossRef] [PubMed]

21. Catalano, J.G.; Park, C.; Fenter, P.; Zhang, Z. Simultaneous inner- and outer-sphere arsenate adsorption on corundum and hematite. Geochim. Cosmochim. Acta 2008, 72, 1986-2004. [CrossRef]

22. Trainor, T.P.; Eng, P.J.; Brown, G.E., Jr.; Robinson, I.K.; Santis, M.D. Crystal truncation rod diffraction study of the $\alpha-\mathrm{Al}_{2} \mathrm{O}_{3}(1 \overline{1} 02)$ surface. Surf. Sci. 2002, 496, 238-250. [CrossRef]

23. Mason, S.E.; Iceman, C.R.; Trainor, T.P.; Chaka, A.M. Density functional theory study of clean, hydrated, and defective alumina (11̄02) surfaces. Phys. Rev. B 2010, 81, 760-762.

24. Lo, C.S.; Tanwar, K.S.; Chaka, A.M.; Trainor, T.P. Density functional theory study of the clean and hydrated hematite (11̄02) surfaces. Phys. Rev. B 2007, 75, 103-112.

25. Tanwar, K.S.; Catalano, J.G.; Petitto, S.C.; Ghose, S.K.; Eng, P.J.; Trainor, T.P. Hydrated $\alpha-\mathrm{Fe}_{2} \mathrm{O}_{3}$ surface structure: Role of surface preparation. Surf. Sci. 2007, 601, L59-L64. [CrossRef]

26. Fulton, J.L.; Bylaska, E.J.; Bogatko, S.; Balasubramanian, M.; Cauet, E.; Schenter, G.K.; Weare, J.H. Near-quantitative agreement of model-free DFT-MD predictions with XAFS observations of the hydration structure of highly charged transition-metal ions. Phys. Chem. Lett. 2012, 3, 2588-2593. [CrossRef] [PubMed]

27. Bargar, J.R.; Towle, S.N.; Brown, G.E., Jr.; Parks, G.A. XAFS and bond-valence determination of the structures and compositions of surface functional groups and $\mathrm{Pb}$ (II) and $\mathrm{Co}$ (II) sorption products on single-crystal $\alpha-\mathrm{Al}_{2} \mathrm{O}_{3}$. J. Colloid Interface Sci. 1997, 185, 473-492. [CrossRef] [PubMed]

28. Brown, I.D. Recent developments in the bond valence model of inorganic bonding. Phys. Chem. Miner. 1987, 15, 30-34. [CrossRef]

29. Brown, I.D.; Altermatt, D. Bond-valence parameters obtained from a systematic analysis of the inorganic crystal structure database. Acta Cryst. 1985, B41, 244-247. [CrossRef]

30. Brown, I.D. Recent developments in the methods and applications of the bond valence model. Chem. Rev. 2009, 109, 6858-6919. [CrossRef] [PubMed]

31. Chen, Y.; Bylaska, E.J.; Weare, J.H. Weakly bound water structure, bond valence saturation and water dynamics at the goethite (100) surface/aqueous interface: Ab initio dynamical simulations. Geochem. Trans. 2017, 18, 3. [CrossRef] [PubMed]

32. Pauling, L. The principles determining the structure of complex ionic crystals. J. Am. Chem. Soc. 1929, 51, 1010-1026. [CrossRef]

33. Hiemstra, T.; Van Riemsdijk, W.H. A surface structural approach to ion adsorption: The charge distribution (CD) model. J. Colloid Interface Sci. 1996, 179, 488-508. [CrossRef]

34. Leung, K.; Nielsen, I.M.B.; Criscenti, L.J. Elucidating the bimodal acid-base behavior of the water-silica interface from first principles. J. Am. Chem. Soc. 2009, 131, 18358-18365. [CrossRef] [PubMed]

35. Kwon, K.D.; Sposito, G. Dirac's dream: Understanding metal sorption by geomedia using density functional theory. Chem. Geol. 2017, 464, 4-13. [CrossRef]

36. Mason, S.E.; Trainor, T.P.; Goffinet, C.J. DFT study of $\mathrm{Sb}(\mathrm{III})$ and $\mathrm{Sb}(\mathrm{V})$ adsorption and heterogeneous oxidation on hydrated oxide surfaces. Comput. Theor. Chem. 2012, 987, 103-114. [CrossRef]

37. Blanchard, M.; Morin, G.; Lazzeri, M.; Balan, E.; Dabo, I. First-principles simulation of arsenate adsorption on the (11̄2) surface of hematite. Geochim. Cosmochim. Acta 2012, 86, 182-195. [CrossRef]

38. Mason, S.E.; Corum, K.W.; Ramadugu, S.K. Fundamental insights about environmental interface reactivity from DFT calculations of geochemical model systems. Surf. Sci. 2015, 631, 48-56. [CrossRef]

39. Lejaeghere, K.; Bihlmayer, G.; Bjorkman, T.; Blaha, P.; Blugel, S.; Blum, V.; Caliste, D.; Castelli, I.E.; Clark, S.J.; Dal Corso, A.; et al. Reproducibility in density functional theory calculations of solids. Science 2016, 351, aad3000. [CrossRef] [PubMed] 
40. Garrity, K.F.; Bennett, J.W.; Rabe, K.M.; Vanderbilt, D. Pseudopotentials for high-throughput DFT calculations. Comput. Mater. Sci. 2014, 81, 446-452. [CrossRef]

41. Baltrusaitis, J.; Jensen, J.H.; Grassian, V.H. FT-IR spectroscopy combined with isotope labeling and quantum chemical calculations to investigate adsorbed bicarbonate formation following reaction of carbon dioxide with surface hydroxyl groups on $\mathrm{Fe}_{2} \mathrm{O}_{3}$ and $\mathrm{Al}_{2} \mathrm{O}_{3}$. J. Phys. Chem. B 2006, 110, 12005-12016. [CrossRef] [PubMed]

42. Pierre-Louis, A.M.; Hausner, D.B.; Bhandari, N.; Li, W.; Kim, J.; Kubicki, J.D.; Strongin, D. Adsorption of carbon dioxide on Al/Fe oxyhydroxide. J. Colloid Interface Sci. 2013, 400, 1-10. [CrossRef] [PubMed]

43. Pahlavan, F.; Pakiari, A.H. DFT study of the chlorine promotion effect on the ethylene adsorption over iron clusters. J. Mol. Graph. Modell. 2016, 66, 58-66. [CrossRef] [PubMed]

44. Tamijani, A.A.; Salam, A.; de Lara-Castells, M.P. Adsorption of noble-gas atoms on the $\mathrm{TiO}_{2}(110)$ surface: An ab initio-assisted study with van der Waals-corrected DFT. J. Phys. Chem. C 2016, 120, 18126-18139. [CrossRef]

45. Nordstrom, D.K. Public health-Worldwide occurrences of arsenic in ground water. Science 2002, 296, 2143-2145. [CrossRef] [PubMed]

46. Hopenhayn, C. Arsenic in drinking water: Impact on human health. Elements 2006, 2, 103-107. [CrossRef]

47. Sarkar, S.; Greenleaf, J.E.; Gupta, A.; Ghosh, D.; Blaney, L.M.; Bandyopadhyay, P.; Biswas, R.K.; Dutta, A.K.; SenGupta, A.K. Evolution of community-based arsenic removal systems in remote villages in West Bengal, India: Assessment of decade-long operation. Water Res. 2010, 44, 5813-5822. [CrossRef] [PubMed]

48. Chakraborti, D.; Rahman, M.M.; Das, B.; Murrill, M.; Dey, S.; Mukherjee, S.C.; Dhar, R.K.; Biswas, B.K.; Chowdhury, U.K.; Roy, S.; et al. Status of groundwater arsenic contamination in bangladesh: A 14-year study report. Water Res. 2010, 44, 5789-5802. [CrossRef] [PubMed]

49. Mohan, D.; Pittman, C.U. Arsenic removal from water/wastewater using adsorbents-A critical review. J. Hazard. Mater. 2007, 142, 1-53. [CrossRef] [PubMed]

50. Berg, M.; Tran, H.C.; Nguyen, T.C.; Pham, H.V.; Schertenleib, R.; Giger, W. Arsenic contamination of groundwater and drinking water in vietnam: A human health threat. Environ. Sci. Technol. 2001, 35, 2621-2626. [CrossRef] [PubMed]

51. Ng, J.C.; Wang, J.P.; Shraim, A. A global health problem caused by arsenic from natural sources. Chemosphere 2003, 52, 1353-1359. [CrossRef]

52. Yoshida, T.; Yamauchi, H.; Sun, G.F. Chronic health effects in people exposed to arsenic via the drinking water: Dose-response relationships in review. Toxicol. Appl. Pharmacol. 2004, 198, 243-252. [CrossRef] [PubMed]

53. Bissen, M.; Frimmel, F.H. Arsenic-A review. Part 1: Occurrence, toxicity, speciation, mobility. Acta Hydrochim. Hydrobiol. 2003, 31, 9-18. [CrossRef]

54. Saha, J.C.; Dikshit, A.K.; Bandyopadhyay, M.; Saha, K.C. A review of arsenic poisoning and its effects on human health. Crit. Rev. Environ. Sci. Technol. 1999, 29, 281-313. [CrossRef]

55. Wilson, S.C.; Lockwood, P.V.; Ashley, P.M.; Tighe, M. The chemistry and behaviour of antimony in the soil environment with comparisons to arsenic: A critical review. Environ. Pollut. 2010, 158, 1169-1181. [CrossRef] [PubMed]

56. Delley, B. An all-electron numerical-method for solving the local density functional for polyatomic-molecules. J. Chem. Phys. 1990, 92, 508-517. [CrossRef]

57. Delley, B. From molecules to solids with the dmol(3) approach. J. Chem. Phys. 2000, 113, $7756-7764$. [CrossRef]

58. Perdew, J.P.; Burke, K.; Ernzerhof, M. Generalized gradient approximation made simple. Phys. Rev. Lett. 1996, 77, 3865-3868. [CrossRef] [PubMed]

59. Wyckoff, R.W.G. Crystal Structures; John Wiley and Sons: Hoboken, NJ, USA, 1964; Volume 2.

60. Meyer, R.; Ge, Q.F.; Lockemeyer, J.; Yeates, R.; Lemanski, M.; Reinalda, D.; Neurock, M. An ab initio analysis of adsorption and diffusion of silver atoms on alumina surfaces. Surf. Sci. 2007, 601, 134-145. [CrossRef]

61. Hinnemann, B.; Carter, E.A. Adsorption of Al, O, Hf, Y, Pt, and $\mathrm{S}$ atoms on $\alpha-\mathrm{Al}_{2} \mathrm{O}_{3}(0001)$. J. Phys. Chem. C 2007, 111, 7105-7126. [CrossRef]

62. Wang, X.G.; Chaka, A.; Scheffler, M. Effect of the environment on $\alpha-\mathrm{Al}_{2} \mathrm{O}_{3}$ (0001) surface structures. Phys. Rev. Lett. 2000, 84, 3650-3653. [CrossRef] [PubMed] 
63. Ruberto, C.; Yourdshahyan, Y.; Lundqvist, B.I. Surface properties of metastable alumina: A comparative study of $\mathrm{k}$ - and $\alpha-\mathrm{Al}_{2} \mathrm{O}_{3}$. Phys. Rev. B 2003, 67, 195412. [CrossRef]

64. Mason, S.E.; Sokol, E.A.; Cooper, V.R.; Rappe, A.M. Spontaneous formation of dipolar metal nanoclusters. J. Phys. Chem. A 2009, 113, 4134-4137. [CrossRef] [PubMed]

65. Klamt, A.; Schuurmann, G. COSMO-A new approach to dielectric screening in solvents with explicit expressions for the screening energy and its gradient. J. Chem. Soc. Perkin Trans. 1993, 2, 799-805. [CrossRef]

66. Corum, K.W.; Huang, X.; Bennett, J.W.; Mason, S.E. Systematic density functional theory study of the structural and electronic properties of constrained and fully relaxed $\left(\begin{array}{lll}0 & 0 & 1\end{array}\right)$ surfaces of alumina and hematite. Mol. Simul. 2017, 43, 406-419. [CrossRef]

67. Shimizu, M.; Ginder-Vogel, M.; Parikh, S.J.; Sparks, D.L. Molecular scale assessment of methylarsenic sorption on aluminum oxide. Environ. Sci. Technol. 2010, 44, 612-617. [CrossRef] [PubMed]

68. Ramadugu, S.K.; Mason, S.E. DFT study of antimony(V) oxyanion adsorption on $\alpha-\mathrm{Al}_{2} \mathrm{O}_{3}(1 \overline{1} 02)$. J. Phys. Chem. C 2015, 119, 18149-18159. [CrossRef]

69. Abbaspour Tamijani, A.; Ebrahimiaqda, E. Molecule-decorated rutile-type $\mathrm{ZnF}_{2}$ (110): A periodic DFT study. Surf. Sci. 2017, 662, 34-41. [CrossRef]

70. Abbaspour Tamijani, A.; Ebrahimiaqda, E. Cleavage of rutile $\mathrm{SiO}_{2}$ hemi-crystals: Insights from first-principles investigations. Solid State Sci. 2017, 67, 119-124. [CrossRef]

71. Abbaspour Tamijani, A.; Ebrahimiaqda, E. (110) facet of rutile-structured $\mathrm{GeO}_{2}$ : An ab initio investigation. Mol. Phys. 2017, 115, 1598-1605. [CrossRef]

(C) 2018 by the authors. Licensee MDPI, Basel, Switzerland. This article is an open access article distributed under the terms and conditions of the Creative Commons Attribution (CC BY) license (http:/ / creativecommons.org/licenses/by/4.0/). 